\title{
FYHE
}

The International J ournal of the First Year in Higher Education ISSN: $1838-2959$

Volume 5, Issue 2, pp. 57-68

August 2014

\section{"It might have worked for you but ..." Evaluating the efficacy of a first year support strategy in multiple units and disciplines}

Anna Potter and Lee-Anne Bye

University of the Sunshine Coast, Sippy Downs, Australia

\begin{abstract}
This paper describes how a successful pilot project for a first-year support strategy designed to help at risk students develop self-management and problem-solving capabilities was expanded into a much larger project, at a regional university with a diverse student cohort. The whole-of-institution project included the implementation of the strategy across several schools and disciplines. The strategy involved students who had failed or barely passed an early assessment item filling out a reflective workbook and participating in an intensive academic planning discussion with their tutor. Its use was found to be highly effective in the areas of retention and academic performance in most of the units in which it was implemented. Much of its success hinged, however, on the commitment and enthusiasm of participating teaching staff.
\end{abstract}

\section{Please cite this article as:}

Potter, A., \& Bye, L. (2014). "It might have worked for you but ..." Evaluating the efficacy of a first year support strategy in multiple units and disciplines. The International Journal of the First Year in Higher Education, 5(2), 57-68. doi: 10.5204/intjfyhe.v5i2.232

This article has been peer reviewed and accepted for publication in Int J FYHE. Please see the Editoria Policies under the 'About' section of the Journal website for further information.

(C) Copyright of articles is retained by author/s. As an open access journal, articles are free to use, with proper attribution, in educational and other non-commercial settings. ISSN: 1838-2959 


\section{Introduction}

Attrition rates among first-year students remain a pressing issue for all institutions and their students. At our own institution, a regional university that has just undergone a period of rapid expansion, considerable efforts have been made in recent years to increase and improve support strategies for first-year students. Attrition rates remain, nonetheless, some of the highest in the sector, undermining efforts to ensure a high quality student experience and extend our students' learning opportunities in the region. While a great deal of work has been undertaken in the design and application of first-year support strategies by many staff at our institution, the implementation of these strategies has, at times, been fragmented and lacking in cohesion. As a result, it has not always been clear which first-year supports are the most effective and easily replicated across the institution.

In 2009, a pilot study in a very large foundation unit at our university revealed that an intensive support strategy for atrisk first-year students, originally designed by Professor Keithia Wilson, was highly effective in increasing students' academic performance and persistence. As part of recent efforts to create a more cohesive and coordinated approach to first-year retention at our university, in 2013, this successful pilot was replicated as closely as possible across seven units in several schools and disciplines. Despite some initial misgivings by academic staff, the more widespread use of the strategy was found to be highly effective in improving retention rates and academic performance in participating students. The effective use of the strategy hinged, however, on the extent to which teaching staff normalised and promoted its use to at-risk first year students.

\section{Context}

One of the key recommendations from the Bradley Review (Bradley, Noonan, Nugent \& Scales, 2008) was for universities to increase the proportion of enrolment of students from both the younger age group and low socio-economic status background by 2020 . This recommendation placed universities under new pressures, as an increasingly diverse cohort of first-year students likely to need extra support with transition began to move into higher education (Shah, Lewis, \& Fitzgerald, 2011). Retention is important for both the student and the university. For the student, completing a university degree can result in superior life chances in terms of career opportunities and earning potential; those with an undergraduate qualification can earn up to $25 \%$ (or $\$ 375,000$ over a lifetime) more than those without (Scott, Shah, Grebennikov, \& Singh, 2008). Yet more than one in four first-year students in Australian universities seriously considers dropping out in their first year (Krause, Hartley, James, \& McInnis, 2005). So assisting students to complete their university degree can have a very significant impact on their lives. Further, while not all university withdrawals should be classed as undesirable by either the student or university (Pitkethly \& Prosser, 2001), retention of students is of obvious importance to academic institutions, including our own. Attrition can affect the reputation of the university (La Trobe University, 2012) as well as resulting in economic costs. These costs can be high. Income is lost for every student who is not retained, while the university then has to replace those students in order to fill future loads. The Hobson Retention Report values the loss of an international student at $\$ 17,000$ per year and domestic students at $\$ 8,000$ per year (Adams, Banks, Davis, \& 
Dickson, 2010). A domestic student who leaves after one year results in a loss of income to universities of approximately $\$ 16,000$, or after one semester, of approximately $\$ 20,000$, so universities also have a strong economic incentive to retain their students.

\section{Assessment and retention}

The assessment process plays a crucial role in a student's first year experience, while assessment results provide important clues about a student's levels of engagement and academic preparedness. Lizzio and Wilson (2010) note that academic performance is an important indicator of the level of a student's integration, suggesting that low academic performance may be a sign of existing or resulting disengagement. A student's lower academic achievements in their first semester at university can also be indicative of their increased risk of attrition (Murtaugh, Burns, \& Schuster, 1999). Indeed, Tinto cites studies which show grade performance as "the single most important factors in predicting persistence" (Tinto, 1975, p. 104). At our own institution, one of the top reported drivers of student attrition was first-year students not feeling ready or prepared for university life (Best \& Wilkinson, 2011). This phenomenon is by no means unique; La Trobe university rated it as one of the factors linked to students being more likely to withdraw from university studies (La Trobe University, 2012). Lack of preparedness can include lower ability, poor study strategies, external locus of control and lower self-esteem (Grimes, 1997). A related factor in poor academic performance is an underestimation, not only of skill level, but also of the time commitment and effort required for university. Nonetheless some students now focus on limiting their academic work load, spending less time attending lectures and completing assessment while continuing to expect reasonable grades (Sawon, Pembroke, \& Wille, 2012). A lack of time on task inevitably affects student learning and can be a leading cause of assessment failure, particularly at first year. Given the connections between academic performance and attrition, interventions which enhance students' preparedness to study often lead to improvements in retention (Spence, 2012). Therefore, poor academic performance revealed through the assessment process has considerable diagnostic value for assessors, particularly in attempting to evaluate levels of engagement and vulnerability to attrition.

Despite its value as a diagnostic tool to academic staff, any assessment process that ends in poorer than expected results may trigger a crisis response that puts a student at-risk. For first-year students, poor performance on first assessment items can be a "watershed experience" often revealing the gulf between student expectations and actual achievement. When marks are lower than anticipated, the ensuing disappointment can affect student confidence, commitment and ongoing academic performance (Krause et al., 2005; Wilson \& Lizzio, 2008). Therefore, a "failure" event, sparking off dissatisfaction with academic experience, may have a negative influence. Lizzio and Wilson (2013) note that students often place considerable meaning on early assessment marks, using them to gauge their perceived ability for university as well as their sense of worth and belonging. Wilson (2009) lists low academic self-confidence as one of the two strongest predictors of a student failing to return in second semester while student satisfaction with academic experiences has been found to exert an influence on a student's decision to remain in the course (Legg \& Wilson, 2009). Yet, less than a third of Australian students take the initiative of 
seeking help from academic staff (Sawon et al., 2012). If the institution can assist students to cope with this event, and strengthen their academic confidence and self-efficacy, they will feel better prepared for future assessments (Lizzio \& Wilson, 2013). Thus poor early assessment results can have considerable ramifications for first-year students. They can make students feel they are ill-qualified for tertiary study, rendering them vulnerable to attrition. Alternatively with appropriate support after assessment failure, students can become more confident and more able to self-regulate.

An assessment failure event clearly provides an opportunity to address issues of academic unpreparedness and low selfconfidence in students by offering specific feedback and support. In this way, first-year students can be helped to become more skilled and resilient learners. Indeed support and feedback are institutional conditions which are positively related to student persistence, which can in turn lead to student retention (Tinto, 2005). For instance Kuh (2003) notes that feedback on academic writing can enable a student to become adept at this skill, although feedback which does not explain to students how to bridge the gap between their work and the standard of work required for better grades is largely ineffective (Potter \& Lynch, 2008). Providing appropriate feedback on students' work requires a commitment by the institution to allocate time and resources, which may be difficult in a climate of multiple priorities (Kuh, 2003). Nonetheless despite the inevitable pressures that exist in the allocation of resources, it has been argued that an emphasis on educating students and equipping them with "the skills and dispositions to become effective learners at university" (Pitkethly \& Prosser, 2001, p. 187) will alleviate a number of retention stressors. Investment of resources in intensive feedback and support strategies therefore makes economic sense, as well as contributing to a positive first year experience for at-risk students.

One means of providing direct feedback and support, increasing student confidence and motivation, and of building relationships, is an intrusive advising strategy developed by Keithia Wilson and Alf Lizzio. The strategy is an "academic recovery process" for students who fail or marginally pass an early assessment item and who therefore may be at risk of non-continuation. Its use assists first-year students in the development of self-regulatory and reflective behaviours. The strategy initially involves an individual self-reflection task, followed by an extended consultation with the tutor, which culminates in the development of specific goals and a clear action plan. In one of its earliest incarnations, participating students achieved higher overall academic results in the unit ${ }^{1}$ in which it was used than those who were invited but did not participate (Lizzio \& Wilson, 2008). Given the link between academic performance and retention, this intervention appears to offer significant benefits.

In 2009, Wilson and Lizzio's (2008) intervention strategy was trialled at our university in a pilot study in a large Communication foundation unit (Potter \& Parkinson, 2010). The assessment that triggered the intervention was a 1,000 word essay weighted at $25 \%$ of the unit's overall

\footnotetext{
1 A semester long teaching activity with synonyms across Australasia of "subject", "course" and "paper".
}

60 | The International J ournal of the First Year in Higher Education, 5(2) August, 2014 
marks. The pilot project saw students who failed or barely passed their first major piece of assessment invited to participate in an academic planning process. The students who accepted our invitation completed a reflective workbook before participating in a forty five minute academic advising discussion with their tutor. The process concluded with action planning and where appropriate, referral to student services or other means of support. The pilot study found that the students who failed or just passed an early assessment item were twice as likely to pass the unit overall if they had participated in the pilot study, compared to those students of a similar ability who did not take part in the project. Participants also reported higher levels of connectedness to their tutor, willingness to seek help and academic confidence (Potter \& Parkinson).

In 2013, as part of efforts to introduce a more cohesive and whole-of-institution approach to first-year retention, funding was provided to trial the strategy across a wider range of units and disciplines, which included Communication, English Literature, Indigenous Studies, Management, Mathematics, Tourism and Public Health. While participation in the broader trial was voluntary, not all of the academic staff recruited to the expanded study were convinced the strategy would be effective for their student cohort. A tendency to view student attrition as connected to student deficit was noticeable among some, which meant a number of academic staff were required to re-evaluate and re-direct their own teaching practice as part of their involvement in the project. In the broader implementation of the strategy, student take up rates varied considerably between units, ranging from as low as $7 \%$ in one, to $70 \%$ in another. The degree to which academic staff normalised the use of support strategies may well explain the significant variations in uptakes rates.

In the whole-of-institution project, the 2009 pilot project was replicated as closely as possible across seven units, despite the obvious differences in assessment methods and tasks. Two rules applied to the assessment task that would trigger the intervention: it had to be weighted at a minimum of ten percent of the overall grade and to be submitted by students prior to week 7. Most of the assessment tasks were weighted at $20 \%$, with one at $12.5 \%$ and one at 30\%; assessment types included a short exam, online quiz, tutorial response, report and short essay. Students who failed or just passed their respective assessment items were invited to attend an academic planning discussion with their own tutor, having been asked to complete a reflective workbook before their appointment. Academic staff were encouraged to normalise and promote the strategy and to encourage help-seeking behaviours among their students. Funding was supplied to enable sessional teaching colleagues to be paid for the academic planning discussions while for ongoing academic staff, first-year support activities generally fall under general teaching and administrative responsibilities. All staff received professional development in the strategy's use in a workshop delivered by Professor Keithia Wilson as well as ongoing support and advice from the authors as they implemented the strategy. The research question was "How effective is Wilson and Lizzio's strategy in contributing to the academic success and persistence of first year students across a range of disciplines in one institution?" Data were collected from three sources: a student workbook which included general responses and an evaluation of the process; an online student survey questionnaire; and staff focus groups and interviews. 


\section{Findings of the whole of institution project}

Broadly, the use of the strategy across a wide range of disciplines confirmed the findings of the original pilot project at our institution, despite disciplinary difference and the wider range of assessment tasks used as the strategy trigger. Across the seven units, 478 students were offered the strategy, with 102 students (or $21 \%$ across all units) accepting the offer. The majority of the students $(64 \%)$ were female and fulltime (73\%), $25 \%$ were mature age and $43 \%$ identified as first-in-family. The results of the whole-of-institution project have been organised here under three key themes, better student academic performance through enhanced student capacity, improved student retention, and improved communication processes and leadership capacity for academic staff.

\section{Better academic performance through enhanced capacity building}

The strategy had a measurable impact on students' academic performance across all the units in which it was used. Broadly, across all units on average, $76 \%$ of students who took part in the strategy passed the unit compared to $56 \%$ of students of a similar academic performance who chose not to participate (see Figures 1 and 2). The aggregated data across all units show that participating students recovered to the point where their overall academic performance in the unit was commensurate with the overall student cohort (see Figure 3). Further, the reflective workbook allows students to identify hindrances to their own academic performance, and strategies for overcoming these hindrances. The most frequently mentioned of these were time management and academic skills (see
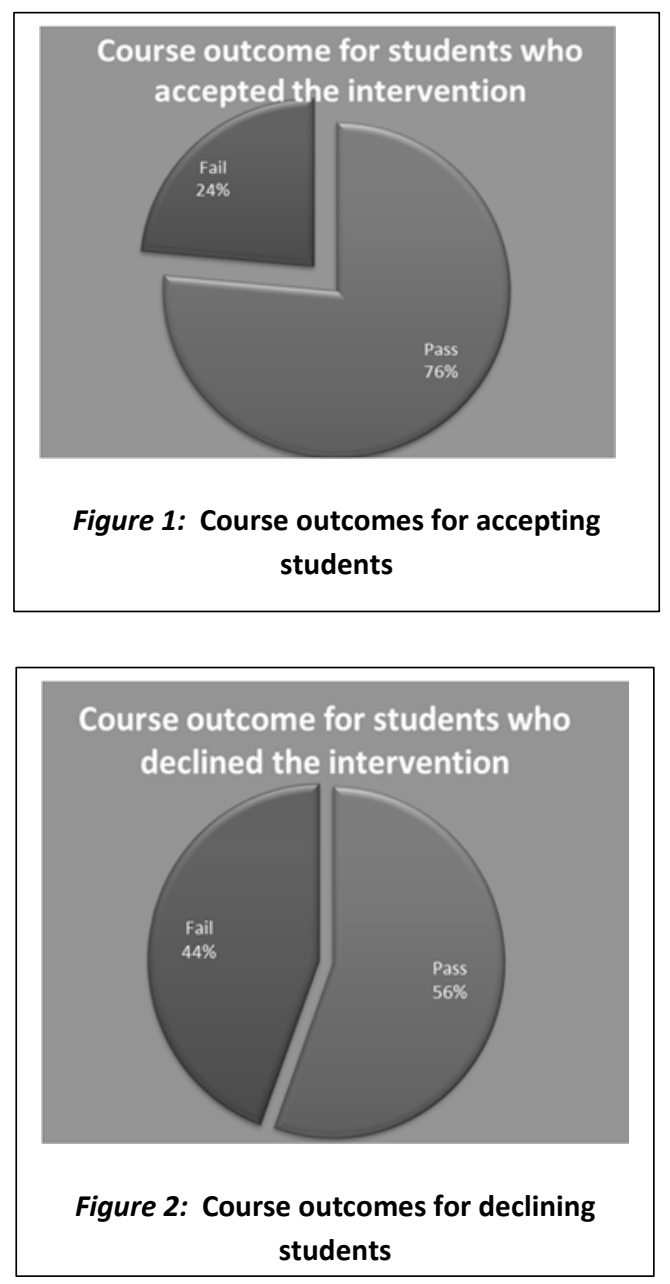

Figure 4). The benefits of students identifying barriers to their success and putting in place strategies to remove those barriers, such as time management and time on task, may also travel beyond the particular unit in which the student undertook the academic planning sessions. Qualitative comments from teaching staff about subsequent academic performances included:

- The students all did much better in the next assessment piece.

- It encouraged student attendance. 
- The workbook is a good analytical tool that focuses the students.

- The international students really benefited from participation in the strategy.

- It dispels the myth that you have to have some in built high intelligence to succeed

- $\quad$ Every workbook moved these students forward, they all did better in the next piece.
The development of these attributes in this student cohort could also be expected to have flow on effects beyond the particular unit in which the strategy was implemented, particularly feelings of connectivity and a sense that the university cares about them. Qualitative comments from students included:

- Helped me organise a suitable work plan to study.

- Useful, good tips and structure from experienced workers.

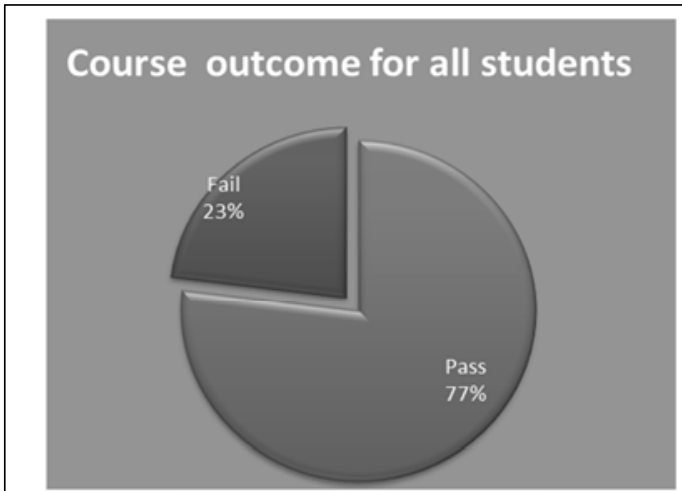

Figure 3 Course outcomes for all students (Based on 5 of the 7 courses where this data was available)

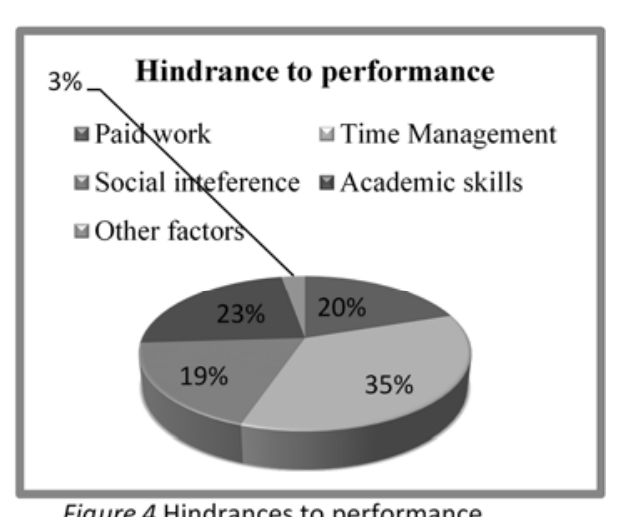

Figure 4 Hindrances to performance
One reason for the improvement in academic performance amongst the students who participated in the planning sessions may be the inherent capacity building factored into the workbook. Evidence of this enhanced capacity was found in the responses to the workbook evaluation questionnaire. Students who took part in the academic planning discussions with their tutor reported higher levels of motivation, confidence, help seeking behaviours, a greater awareness of the expectations of tertiary assessment, a better understanding of their own approach and feelings of being more connected to their tutors (see Figure 5).
- It made me feel better about my assignment and helped me realise why I had gotten the marks I did.

- Good, really helped me understand better and feel like I have a good communication line with my tutor.

- Very good. It helped me a lot and encouraged me to work a bit harder and approach it different and immediately improved my grades.

No negative comments were forthcoming from the survey or workbook, apart from one student noting that the sessions were not always offered at suitable times. The increased levels of motivation, confidence, 


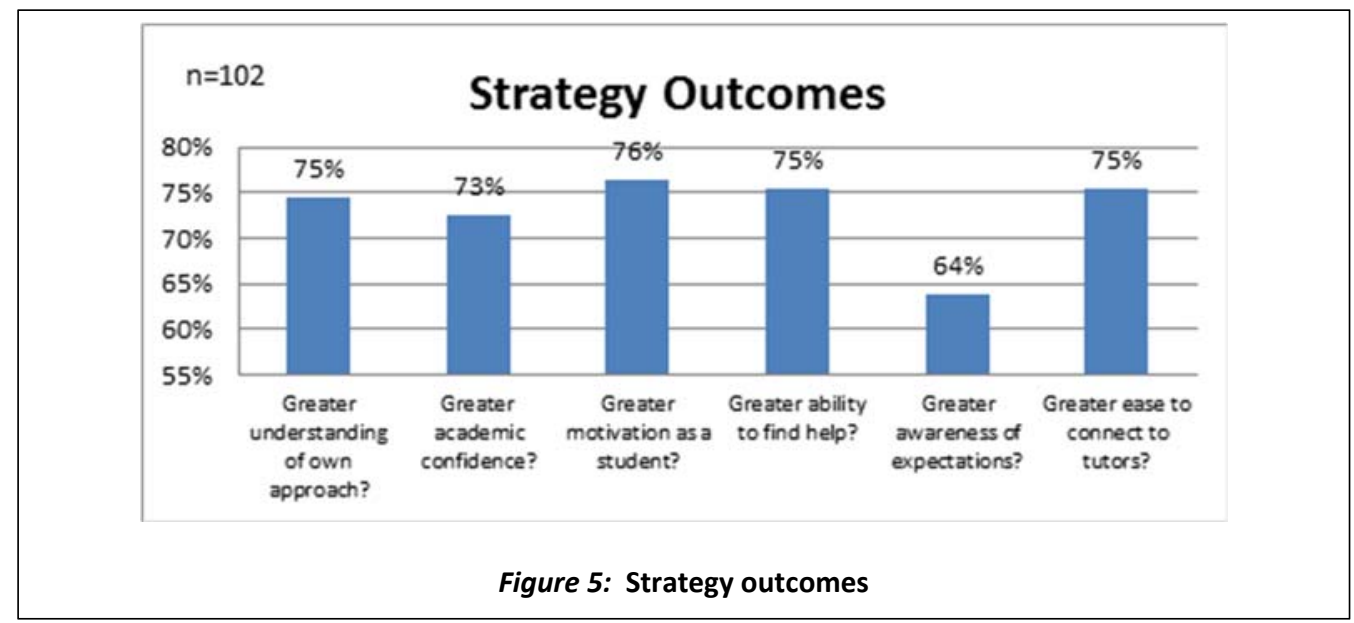

greater awareness of expectations and helpseeking behaviours as reported by all participating students are extremely important for a successful first-year transition. There are therefore direct and indirect benefits to students who participate in the strategy which directly relate to their likelihood of deciding to leave tertiary education. Early identification of academically at-risk students who then participate in the strategy appears to help those students improve their subsequent academic performance through enhanced capacity.

Increased retention of first year students directly involved in this project.

There is some evidence that the strategy had an impact on student attrition. At the end of the planning session, students were asked to rate a number of categories on a "before intervention" and "after intervention" 5-item Likert scale ranging from "not at all" up to "very". The evaluations provided a "before" and "after" comparison. One set of these questions asked: "How likely were you to withdraw or leave university before (and then after) this exercise?" Students who rated themselves at 3 or higher on this scale were deemed "atrisk". As seen below 20 students assessed themselves as having been significantly atrisk prior to the session, but 14 of these rated the "after" question much lower. Only six students still identified as at-risk at the end of the session. This result shows a significant reduction in the numbers of students who self-identified as being at risk, (with a reminder that for every student who is retained in their first semester there is a retention of at least $\$ 20,000$ per student for the university). The later online student survey results from 18 students who participated in the strategy confirmed this finding; 10 of those students (over half of the responders) stated that the academic planning discussion encouraged them to stay at university. While this does not necessarily mean that these students would have left the university, it does indicate that they were considering this option, and that the intervention changed that mindset.

In order to determine if the attitudes expressed above transferred into behaviour, an analysis of semester 2 (week 5) re-enrolment data was undertaken. Overall re-enrolment rates for those students who participated in an academic

64 | The International J ournal of the First Year in Higher Education, 5(2) August, 2014 
planning discussion were significantly higher (at 92\%) than for those students who declined the session (77\%). So, from the 102 students who participated in the academic planning discussion, only eight of these failed to re-enrol in the following semester. Of the 20 who originally selfidentified as at-risk in their workbook, only three failed to re-enrol. A qualitative student comment from the online survey conducted after the project's completion confirmed the strategy's value to one student:

$$
\begin{aligned}
& \text { It helped me realise I have the potential to } \\
& \text { do well with all my subjects. I am so } \\
& \text { grateful that I was offered this session. I } \\
& \text { was seriously considering deferring or } \\
& \text { dropping out. }
\end{aligned}
$$

Qualitative comments from staff interviews after the project's completion included:

$$
\begin{aligned}
& \text { It will have benefits for the university in } \\
& \text { terms of successful students getting } \\
& \text { through units and not dropping out. The } \\
& \text { retention results can improve and the } \\
& \text { reputation of the university can be helped } \\
& \text { as well. } \\
& \text { If they're passing they're more likely to } \\
& \text { stay enrolled. Keeping students, giving } \\
& \text { them every opportunity to continue to do } \\
& \text { as well as they can so they stay committed } \\
& \text { to their degree, don't get disheartened or } \\
& \text { disillusioned and drop out or drop units or } \\
& \text { drop out altogether. }
\end{aligned}
$$

The above analysis confirms that the strategy's use appears to have some impact on at-risk students' behaviour. The process of reflecting on the causes of their poor academic performance, while strengthening their relationship to their tutor, appears to enable students to improve their self-regulatory behaviours while benefitting from feeling more closely connected to their tutor.
Improved

communication processes and leadership capacity for staff

The use of the strategy also built capacity in participating staff by providing them with professional development, academic leadership opportunities and ongoing support in the strategy's effective implementation. Qualitative comments from staff focus groups and interviews reflected the view that academic staff felt they had benefitted from their participation in the project and included:

- A positive experience that fosters greater connectivity and level of care between student and tutor.

- The payment for sessional staff ensured the process was respected.

- Keithia Wilson's workshop was excellent.

- It changes the way you talk to students and teach them, increasing teaching skills.

- Provides plenty of time to talk to students, helping develop rapport and connection.

- So much more knowledge is gained by the student but also about the student.

- Gained a good insight into own teaching pedagogies, helped identify additional ways of supporting students.

- Creates a connection between student and tutor to promote that lifelong learning.

- Specific personal invitation "intrusive advising" - made it more likely students would take part.

- Helped tutors to understand the pressures their students are under better. 
The use of the strategy improved communication processes between academic staff and their students, with the structured discussion created by the workbook ensuring that academic planning discussions remained focussed and productive. Taking part in the project appears to encourage reflective practice among academic staff, with a number becoming extremely enthusiastic about a strategy which initially they thought illsuited to their students' needs.

\section{Discussion}

The findings of the wider implementation of the strategy are very encouraging and indicate that it is a highly effective support mechanism for first-year students in a variety of disciplines. They suggest that the strategy helps students identify and solve impediments to their academic success, self-regulate their behaviour and thus achieve improved academic outcomes. The intervention is also extremely effective at enhancing first year students' sense of connectivity to their tutors, and concomitant ability to seek help. The benefits for students of being able to identify impediments to their academic success including poor time management, lack of time on task and an insufficient skill set are like to be felt beyond the specific unit in which students took part in the strategy. Similarly a greater capacity to self-regulate their behaviour will broadly benefit firstyear students during their transition to higher education as well as improving the likelihood of their completing the studies.

Academic leadership remains crucial to the strategy's effective implementation and uptake by first-year students, however. Leadership begins with the establishment of expectations and commitment to firstyear support strategies among a unit's teaching staff; this was an important factor in the success of the strategy. The success and uptake by staff was evident in some units where the Unit Coordinator clearly expressed both the vision-the importance of the strategy for the students and the unit-as well as communicating a clear expectation that staff would fully commit to the process. Where this occurred, the outcome was that all tutors participated fully, seeing multiple students for planning sessions. Where the vision and an expectation of commitment from tutoring staff were not fully communicated, the uptake was irregular. Staff commitment from both the Unit Coordinator and the tutoring staff was therefore a linchpin to the success of the strategy. In some units, the Unit Coordinators saw students for planning sessions while other staff did not participate in the process (placing a large burden on the Coordinator). In other instances, some teaching staff responded to the vision and expectation and met with many students, while other staff only saw a few students or none at all.

One potential barrier to staff uptake was the concern at the time and workload that may be needed for its effective implementation. This was a concern particularly for staff with heavy teaching loads, with a high number of students being invited and potentially needing to be seen in planning sessions. This concern was expressed by a number of staff, although most of the fears were not realised. Student uptake of the strategy is generally fairly low; the 2009 pilot and the whole of institution implementation confirmed that take up rates are often less than $50 \%$, and generally rest around 30\%. Significant variations can occur, however, in uptake rates, with a small number of units having an extremely high number of students accepting (up to 70\%). For these staff, we would suggest processes such as marking support need to be in place, to enable them to cope with the additional 
workload. It was noted that the units with the high numbers of student uptake were also those units where the Coordinator had clearly communicated the vision and expectation and where all the tutoring staff had committed to the process.

It is worthwhile considering the range of barriers that might exist in terms of student uptake, in order to improve this outcome. Some of these factors may lie with the university/unit/staff member, for example: the strength of the existing connection to the tutor, the type of unit, the length of the tutorial, the weighting of the assessment, the degree to which the process was normalised and introduced by the Unit Coordinator and tutors in lectures and classes. On the other hand, student factors would also influence uptake. Some factors noted in the staff interviews were: students might not have the extra time to attend during high workload weeks, times offered might not suit students, or students may underestimate the need, thinking they will be fine with the next assessment task. For those who are considering trialling such a strategy themselves, the following points are offered as advice:

- The piece of assessment that triggers the academic planning discussion must have sufficient weighting for its failure to really "matter" to students.

- Its timing must ensure plenty of opportunity for students to recover academically.

- You must have the Unit Coordinator's commitment, and ability to motivate and encourage their teaching team, both of which will underpin the strategy's successful implementation.

\section{Conclusion}

The support strategy described here focusses on helping students at risk of attrition after poor academic performance. The expansion of the initial pilot project into a whole-of-institution project involved the strategy's use across seven units, to reduce student attrition while creating a more cohesive and coordinated model for student retention strategies at our institution. Its broader use demonstrated its efficacy in a variety of student cohorts, providing a robust model for student engagement which is effective across a wide assortment of disciplines. The broad implementation of the strategy that occurred during this project can be replicated across other institutions, providing it is accompanied by appropriate levels of resourcing, professional development, administrative support and, most importantly, academic leadership from participating staff. The evidence indicates that the strategy's use is of benefit not only for the participating students but also for the academic staff who teach them, something which should be highlighted when encouraging its uptake. The financial costs of student attrition also suggest the resources required for the strategy's use bring significant institutional returns.

\section{References}

Adams, T., Banks, M., Davis, D., \& Dickson, J. (2010, October). The Hobsons Retention Project: Context and factor analysis report. Paper presented at the Australian International Education Conference (AIEC), Sydney, Australia. Retrieved from http://www.aiec.idp.com/pdf/2010 AdamsBan ksDaviesDickson Wed 1100 BGallB Paper.pdf

Best, T., \& Wilkinson, H. (2011). Student attrition, 2011 summary. University of the Sunshine Coast, Sippy Downs, Australia.

Bradley, D., Noonan, P., Nugent, H., \& Scales, B. (2008). Review of Australian higher education. Final report. Canberra, Australia: Department of 
Education, Employment and Workplace Relations.

Grimes, S. (1997). Underprepared community college students: Characteristics, persistence, and academic success. Community College Journal of Research and Practice, 21(1), 47-56. doi: $10.1080 / 1066892970210105$

Krause, K-L., Hartley, R., James, R., \& McInnis, C. (2005). The first year experience in Australian universities: Findings from a decade of national studies. Melbourne, Australia: Centre for the Study of Higher Education, University of Melbourne.

Kuh, G. (2003). What we're learning about student engagement from NSSE. Change, 35, 24-32.

La Trobe University. (2012). First Year Experience Plan: 2012-2015. Melbourne, Australia: La Trobe University.

Legg, A., \& Wilson, J. (2009). E-mail from Professor enhances student motivation and attitudes. Teaching of Psychology, 36(3), 205-211. doi: $10.1080 / 00986280902960034$

Lizzio, A., \& Wilson, K. (2008). Feedback on assessment: Students' perceptions of quality and effectiveness. Assessment \& Evaluation in Higher Education, 33(3), 263-275.

Lizzio, A., \& Wilson, K. (2010, June-July). Strengthening commencing students' sense of purpose: Integrating theory and practice. Paper presented at the 13th Pacific Rim First Year in Higher Education Conference, Adelaide, Australia.

Lizzio, A., \& Wilson, K. (2013). Early intervention to support the academic recovery of first-year students at risk of non-continuation. Innovations in Education and Teaching International (aheadof-print), 1-12.

Murtaugh, P., Burns, L., \& Schuster, J. (1999). Predicting the retention of university students. Research in Higher Education, 40(3), 355-371.

Pitkethly, A., \& Prosser, M. (2001). The first year experience project: A model for university-wide change. Higher Education Research and Development, 20(2), 185-198.

Potter, A., \& Lynch, K. (2008, June). Quality feedback on assessment: Apple for the teacher? How first year student perceptions of assessment feedback affect their engagement with study. Paper presented at the 11th Pacific Rim First Year in Higher Education conference, Hobart, Australia.

Potter, A., \& Parkinson, A. (2010, June-July). First year at risk intervention pilot project: An intervention to support first year students experiencing early assessment failure. Paper presented at the 13th
Pacific Rim First Year in Higher Education Conference, Adelaide, Australia. Retrieved from http://www. fyhe. com. au/past papers/papers10/content/pdf B.

Sawon, K., Pembroke, M., \& Wille, P. (2012). An analysis of student characteristics and behaviour in relation to absence from lectures. Journal of Higher Education Policy and Management, 34(6), 575-586. doi: 10.1080/1360080x.2012.716004

Scott G., Shah, M., Grebennikov L., \& Singh, H. (2008). Improving student retention: A University of Western Sydney case study. Journal of Institutional Research 14(1), 1-23.

Shah, M., Lewis, I., \& Fitzgerald, R. (2011). The renewal of quality assurance in Australian higher education: The challenge of balancing academic rigour, equity and quality outcomes. Quality in Higher Education, 17(3), 265-278.

Spence, S. (2012). Operation Student Success: Griffith's student retention strategy 2012 - 2014: Griffith University, Brisbane, Australia.

Tinto, V. (1975). Dropout from higher education: A theoretical synthesis of recent research. Review of Educational Research, 45(1), 89-125. doi: $10.2307 / 1170024$

Tinto, V. (2005, May). Taking student success seriously: Rethinking the first year of college. Paper presented at the Ninth Annual Intersession Academic Affairs Forum, California State University, Fullerton.

Wilson, K. (2009, June-July). Success in first year: The impact of institutional, programmatic and personal interventions on an effective and sustainable first-year student experience. Keynote address presented at the $12^{\text {th }}$ Pacific Rim First Year in Higher Education Conference. Townsville, Australia.

Wilson, K., \& Lizzio, A. (2008, June-July). A 'just in time intervention' to support the academic efficacy of at-risk first year students. Paper presented at the 11th Pacific Rim First Year in Higher Education Conference, Hobart, Australia. 